\title{
Impaired discriminative function in patients with chronic pain measured by variance in straight leg raising
}

\author{
Ann Marie Hoirch BA, Vicky Smith BSc(PT), Sophie Beugnot BSc, Joanne Turner, \\ Richard FH Catchlove MB BS FFARACS MSc
}

\begin{abstract}
AM Hoirch, V Smith, S Beugnot, J Turner, RFH Catchlove. Impaired discriminative function in patients with chronic pain measured by variance in straight leg raising.

Pain Res Manage 1996;1(3):146-148.

Many chronic pain patients seem to have difficulty regulating exercise programs and require detailed, precise instructions of what exercises to do as well as their frequency and timing. This may be due to a lack of information concerning the state of the damaged tissues, which may result from inadequate feedback mechanisms for pain, stretch and position. The straight leg raising test was used as a model of this mechanism, and variance in targeting the end-point of this test was measured in patients with chronic pain and in controls. Variance about the end-point in chronic pain patients was more than three times larger than that in controls. Although chronic pain patients were older, there was no correlation between straight leg raising and age. The implications of these findings to the maintenance of the original injury and the importance of this in the maintenance and continuation of chronic pain states are discussed.
\end{abstract}

Key Words: Chronic pain, Pain mechanisms, Rehabilitation, Straight leg raising

\section{Altération de la fonction discriminante chez les patients souffrant d'une douleur chronique mesurée par la variance lors de la manoeuvre de Lasègue}

RÉSUMÉ : De nombreux patients souffrant de douleurs chroniques semblent avoir de la difficulté à effectuer régulièrement un programme d'exercices et doivent recevoir des instructions précises et détaillées sur le type d'exercices à faire ainsi que sur leur fréquence et leur durée. Ceci peut être dû à un manque d'informations en ce qui concerne l'état des tissus endommagés, ce qui pourrait résulter de mécanismes de rétroaction inadéquats pour la douleur, l'étirement et la position. La manoeuvre de Lasègue a été utilisée comme modèle de ce mécanisme et la variance pour cibler le point-limite de ce test a été mesurée chez les patients souffrant de douleurs chroniques et chez des sujets témoins. La variance concernant le pointlimite chez les patients souffrant de douleurs chroniques était trois fois plus grande que celle observée chez les témoins. Bien que les sujets souffrant de douleurs chroniques aient été plus âgés, on a observé aucune corrélation entre la manoeuvre de Lasègue et l'âge. Les implications de ces constatations dans l'entretien de la blessure d'origine et l'importance de ce dernier facteur dans l'entretien et la prolongation des états de douleurs chroniques sont discutées.
$\mathrm{A}^{\mathrm{s}}$ s clinicians we are often surprised by the difficulty that patients with chronic pain problems have in rehabilitating from relatively minor physical components of a chronic pain syndrome (1-3). We have sometimes noted an apparent inability of chronic pain patients to self-regulate the process of physical rehabilitation, and that detailed instructions of the amount of time to walk, sit up, etc, have been required before rehabilitation can be achieved.

A typical example of this is provided by a patient who was initially seen and treated for reflex sympathetic dystrophy of her left foot and who had a recurrence of back pain from surgically treated idiopathic kyphoscoliosis. During on-going psychotherapy for psychological problems underlying her original complaint, we had the chance to observe her regularly over several years. Because of continuing back pain, the bracing rods in her back were removed and an un-united fusion was successfully regrafted. Recovery proceeded well, she was placed in a brace and later returned to work, but she removed the brace for long periods and would only replace it when the pain became intolerable. It seemed that she could not determine the optimum time to replace

Pain Management Centre and Department of Physiotherapy, Royal Victoria Hospital and McGill University, Montreal, Quebec

Correspondence: Dr Richard FH Catchlove, Director, Pain Management Centre, Royal Victoria Hospital, 687 Pine Avenue West, Suite S10.51,

Montreal, Quebec H3A 1A1. Telephone 514-842-1231 ext 5221, fax 514-843-1723

Received for publication February 12, 1996. Accepted March 26, 1996 
the brace, ie, she had difficulty pacing her recovery. However, when a strictly timed schedule was instituted, which she followed closely, she was able to reduce the use of the brace and ultimately to do without it. This suggested that her internal mechanisms were inadequate to allow her to regulate her rehabilitation freely.

We have also noticed in physiotherapy groups (4) that certain patients seem to have a poor perception of bodily placement during simple exercise regimens. As well, there are reports in physiotherapy literature (5-7) stressing the importance of very structured, graduated, goal-oriented rehabilitation programs $(8,9)$ and the need for patients to learn to pace their activities $(2)$.

To explain these observations, we postulated that the difficulty in rehabilitation from the often relatively minor physical component of a chronic pain problem may be related to inadequate feedback mechanisms for pain, stretch and position. That is, that the discriminative function of these sensations was insufficiently precise to enable patients to limit movements and exercises to stretching and lengthening. We postulated that chronic pain patients would have difficulty 'targeting' or discriminating the end-point of any specific movement, and would show wide variance when the movement was repeatedly performed. We chose the straight leg raising (SLR) test because it requires the exercise of this discriminative function and is a commonly used and reliable test (10). As well, it is very easy to measure the angle attained. However, the object of using this test was not to determine the degree to which a subject's leg can be raised, but rather to measure the variability of this angle when the test was repeatedly performed. We postulated that pain patients would be less capable than controls of defining an end-point.

\section{PATIENTS AND METHODS}

Thirty patients who presented consecutively to the Pain Management Centre of the Royal Victoria Hospital, Montreal, Quebec gave their consent to participate in this study, which was approved by the Hospital Ethics Committee. Patients who had pain in the distribution of the sciatic nerve were excluded. To act as controls, 20 auxiliary staff, nurses and nursing students at the same hospital also agreed to be tested.

The patient lay on his or her back, with the nontested leg bent over a pillow. A screen was placed at the level of the waist to completely screen the patient from viewing his or her leg and the tester. Markers were placed on the leg, and the procedure was video recorded by an independent observer (only the leg was videoed). One of the authors raised the leg steadily. The authors did not instruct patients to call 'stop' at a certain pain level, stretch or similar sensation; they were simply instructed to call 'stop' when they wished to stop the leg raise. The leg was then returned to the resting position. The test was repeated five times for each leg, and the angle obtained for each test was later measured from the video screen. A subgroup of control subjects and the patient group was tested again one week later to determine whether there was any learning curve in targeting the end-point of the SLR.

The measurement from the video recording of the angle obtained was calculated by an author who was blind to the order of procedure. The variability for each set of measurements for each

\begin{tabular}{|lccc|}
\hline $\begin{array}{l}\text { TABLE 1 } \\
\text { Location of pain }\end{array}$ & Males & Females & Total (\%) \\
\hline Site & 4 & 4 & $8(27)$ \\
Back & 4 & 3 & $7(23)$ \\
Low back & 2 & 0 & $2(7)$ \\
Chest & 3 & 2 & $5(17)$ \\
Abdominal & 2 & 4 & $6(20)$ \\
Upper limb & 1 & 0 & $1(3)$ \\
Lower limb & 1 & 0 & $1(3)$ \\
Head & 17 & 13 & $30(100)$ \\
Total & & & \\
\hline
\end{tabular}

\section{TABLE 2}

Mean variances of straight leg raising test

\begin{tabular}{|c|c|c|c|}
\hline Leg & Patients $(n=30)$ & Controls $(n=20)$ & Variance ratio \\
\hline Left & 21.919 .0 & $10.4 \quad 11.3$ & 2.1 \\
\hline Right & 55.563 .9 & 10.316 .1 & 5.4 \\
\hline Combined & $38.7 \quad 41.5$ & 10.313 .7 & 3.8 \\
\hline
\end{tabular}

leg was calculated for each subject and each control. However, calculation of the variance was directly a function of the actual angle obtained, and hence varied in size according to the angle that each patient or control attained.

Because the angle attained was irrelevant to the measurement of the patient's ability to target a given end-point, the variances were recalculated as a percentage of the angle attained for each patient so that the two groups were comparable. The difference in the angles attained was thereby eliminated.

\section{RESULTS}

Thirty patients were tested, 17 males and 13 females, average age 40.7 years (range 18 to 59). The duration of the pain ranged from three months to 30 years, median 26 months. The location of pain in the 30 patients is shown in Table 1 . There were 20 control subjects, nine males and 11 females, average 33.2 years (range 19 to 54).

The average angle ( SD) attained at 'stop' was 57.1 $23.4^{\circ}$ for patients and $88.3^{\circ} 8.5^{\circ}$ for controls. Mean variance ( SD) for patients was left leg 21.9 19.0, right leg 55.5 63.9; mean variance ( $\mathrm{SD}$ ) for controls was left leg 10.4 11.3, right leg 10.316 .1 (Table 2).

To compare SLR measurement variances in the two groups for each leg, a two-way ANOVA (group, leg) for independent groups of unequal sample sizes was performed. There was a significant difference between the combined results (left and right legs) of patients and of controls $(\mathrm{F}=157.76, \mathrm{P}<0.05)$, as well as between the combined values for left and for right legs $(\mathrm{F}=43.64$, $\mathrm{P}<0.05)$. The interaction effect was also significant $(\mathrm{F}=123.2$, $\mathrm{P}<0.05)$. A $t$ test performed on the variances of the left and right legs of the patients found a significant difference $(t=2.718$, $\mathrm{P}<0.01)$.

There was no significant increase in the angle achieved be- 
tween trial 1 and trial 5 for patients, although such an increase was found for the right leg in controls.

In the patient group, age was compared with the variance of each patient by regression analysis. There was no correlation.

\section{DISCUSSION}

This study describes a novel use for the SLR test. Usually, this test is part of the physical examination for low back pain or nerve root entrapment (eg, radiculopathy, sciatica) to determine how far the leg can be raised, and may contribute useful information as part of a comprehensive evaluation of a pain problem. In this study, our interest was not this angle, but the variability of the angle attained during repeated testing.

The results show that patients with chronic pain are less able than control subjects to define the end-point for this specific manoeuvre. The control group was at least twice as precise as the patient group. Why the right leg of chronic pain patients was so much less precise in the SLR test than the left leg is unclear. Perhaps it was related to the patients' pain pathology. It may be worthwhile to determine whether this was an artefact. It is noteworthy that, in the control group, the variances and angles were virtually identical for both legs. It appears that the SLR is a useful tool to evaluate a patient's ability to reproduce a specific movement precisely. The SLR test may prove useful to evaluate rehabilitation programs and other kinds of therapies.

These results are consistent with the concept that a disorder of discriminatory function can contribute to the development and/or maintenance of chronic pain, although the study does not permit us to determine whether this is a primary deficiency or is secondary to the presence of pain. However, the case history cited above and reports in the physiotherapy literature (11) suggest that the postulated disorder is primary, and contributes to the development of chronic pain because these patients are able to self-regulate accurately when precise goals and end-points are provided. Presumably, this is not possible if the difficulty were simply secondary to the pain. We are presently studying the effects of cold pressor pain on SLR variance to answer this question. That study should also help us to determine whether the presence of pain can explain the significantly different angles $\left(57^{\circ}\right.$ versus $\left.88^{\circ}\right)$ obtained by the two groups.

are that physical therapies such as physiotherapy, nerve blocks and TENS may do best when instituted in combination with psychological and social rehabilitative programs.

\section{REFERENCES}

1. Fordyce WE. An operant conditioning method for managing chronic pain. Postgrad Med 1973;53:123-34.

2. Gottlieb HJ, Alperson BL, Koller R, Hockersmith V. An innovative program for the restoration of patients with chronic back pain. Phys Ther 1979;59:996-9.

3. Waddell G, McCulloch JA, Jummel EG, Venner RM. Non-organic physical signs in low back pain. Spine 1980;5:117-25.

4. Gasma A, Braha RED, Catchlove RFH. The use of structured group therapy sessions in the treatment of chronic pain patients. Pain 1985;22:91-6.

5. Doleys DM, Crocker M, Patton D. Response of patients with chronic pain to exercise quotas. Phys Ther 1982;62:1111-4.

6. Tollison CD, Krieger MC, Downie GR. Chronic low back pain: Results of treatments at the pain therapy centre. South Med J 1985;78:1291-5.
More specifically, the altered discriminative function in chronic pain patients may be caused by the phenomenon described by LeBars and colleagues (12) as diffuse, noxious, inhibitory control, in which the chronic pain state acts as a variable heterotopic painful stimulus to inhibit variably awareness of the end-point of the SLR. Should such inhibition occur, it would suggest that abolition or reduction of the chronic pain state allows more precise targeting of the end-point. For instance, nerve blocks, transcutaneous electrical nerve stimulation (TENS) and acupuncture, when combined with goal-oriented, limited physiotherapy and behaviour modification programs, may permit patients to improve their discriminatory function and rehabilitative efforts.

The ability to discriminate precisely between a range of motion that will stretch tissue, but not damage it, is of the utmost importance in maintaining health and physical fitness, and is equally important in regaining health following injury. Presumably this capacity or function is learned during an early stage of human growth and development.

Behaviour modification programs that set goals, emphasize patients' responsibility for themselves, and provide strong emotional support and strong reinforcement to reach pre-set goals (1) may be effective because these manoeuvres help patients to learn discriminative function. Inherent in the setting of a goal is the limit, ie, once the goal has been reached, no more need be done. Doleys et al (5) extended the Fordyce concept by setting the goals as $80 \%$ of a level that patients achieved in the preliminary trials, and then gradually increasing this level as patients reached the goal. They found that patients only learned the exercises they had done and did not generalize the concept of goal-setting. We have planned studies specifically designed to evaluate the ability to learn discriminative function.

Our results also suggest that it is not necessary to invoke the concept of hypochondriasis $(13,14)$ or other mysterious pain mechanisms (15) to explain severe ongoing pain in patients because most major chronic pain states are, in fact, associated with some kind of tissue damage (16). These results raise the possibility that this damage may persist because of inadequate or inappropriate rehabilitative efforts and thereby may remain as a nocigenic source. The implications for chronic pain treatment

7. Siracusano G. The physical therapist's use of exercise in the treatment of chronic pain. J Ortho Sports Phys Ther 1984;6:73-5.

8. Dolce JJ, Crocker MF, Moletteire C, Doleys DM. Exercise quotas, anticipatory concern and self-efficacy expectancies in chronic pain A preliminary report. Pain 1986;24:365-72.

9. Smith P. An educational tool for the patient with chronic pain. Clin Manage Phys Ther 1988;8:10-2.

10. Urban LM. The straight-leg raising test: A review. J Ortho Sports Phys Ther 1981;2:117-33

11. Heinrick RL, Cohen MJ, Naliboff RD, Collins GA, Bonebakker AD. Comparing physical and behaviour therapy for chronic low back pain on physical abilities, psychological distress and patients perceptions. J Behav Med 1985;8:61-78.

12. LeBars D, Dickenson AH, Besson JM, Villaneuva L. Aspects of sensory processing through convergent neurons. In: Yaksh TL, ed. Spinal Afferent Processing. New York: Plenum Press, 1986:456-504.

13. Barskey AJ, Klerman GL. Hypochondriasis, bodily complaints and somatic style. Am J Psychiatr 1983;140:273-83. 
14. Schmidt AJM, Gierlings REH, Peters ML. Environmental and interoceptive influences on chronic low back pain behaviour. Pain 1989;38:137-43.

15. Roy R. The Social Content of the Chronic Pain Sufferer. Toronto:

University of Toronto Press, 1992:6-7.

16. Crook J, Tunks E. Defining the "chronic pain syndrome".

An epidemiological method. Clin J Pain 1985;1:159-63. 


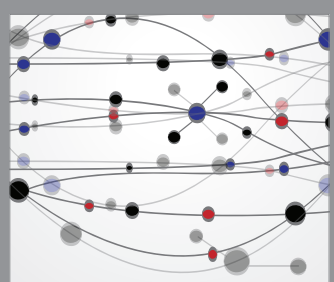

The Scientific World Journal
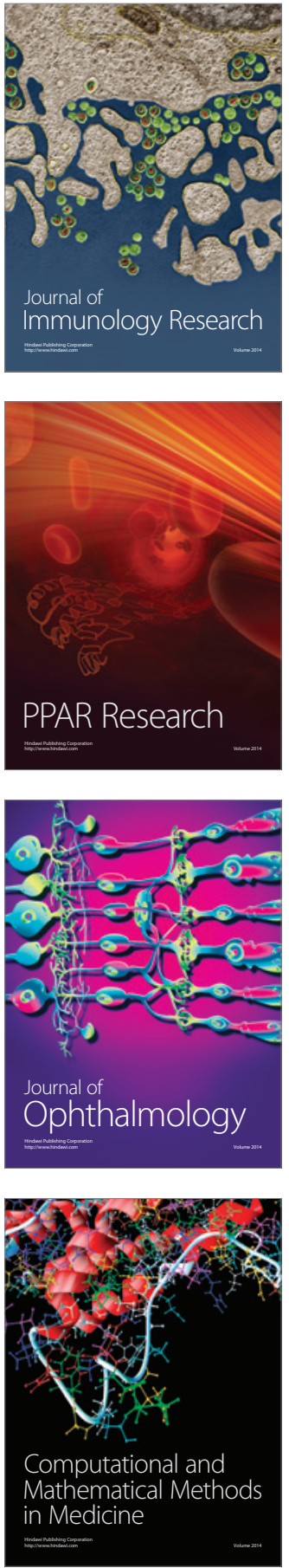

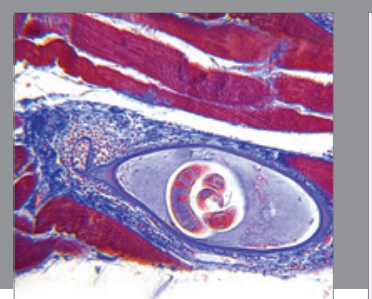

Gastroenterology Research and Practice

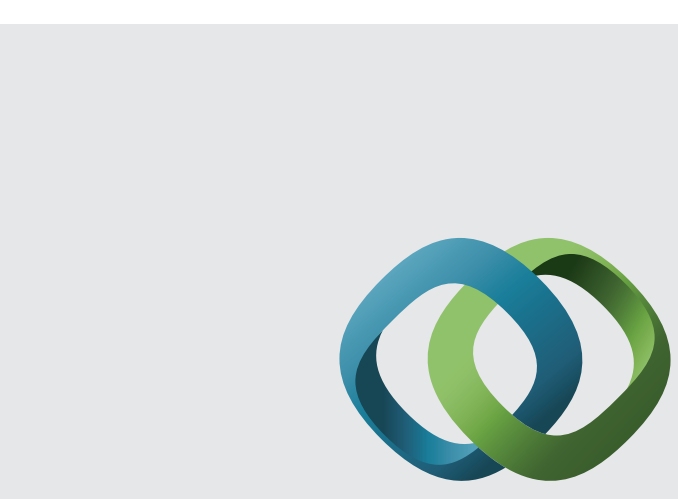

\section{Hindawi}

Submit your manuscripts at

http://www.hindawi.com
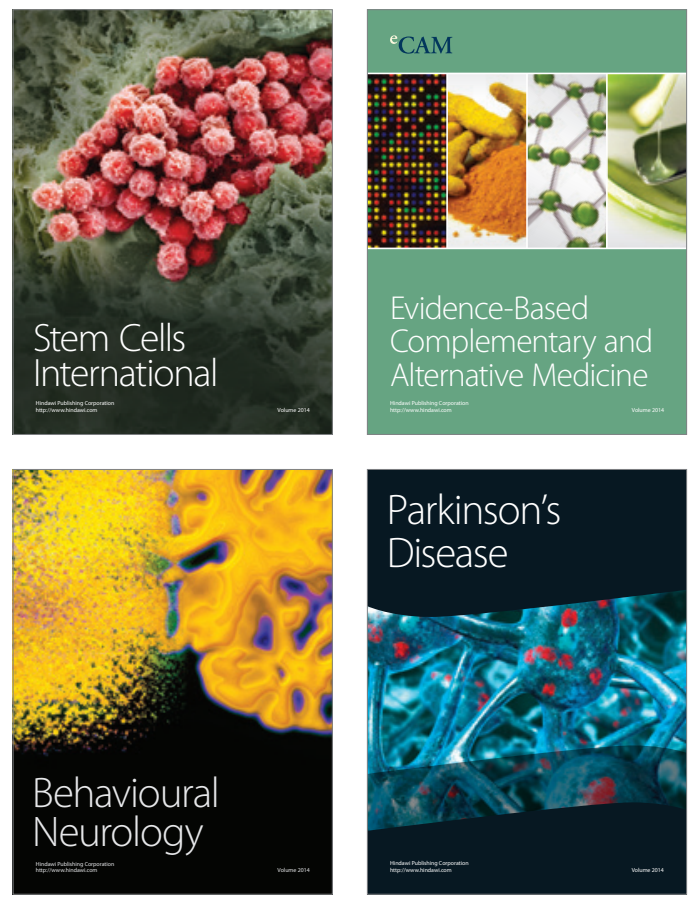
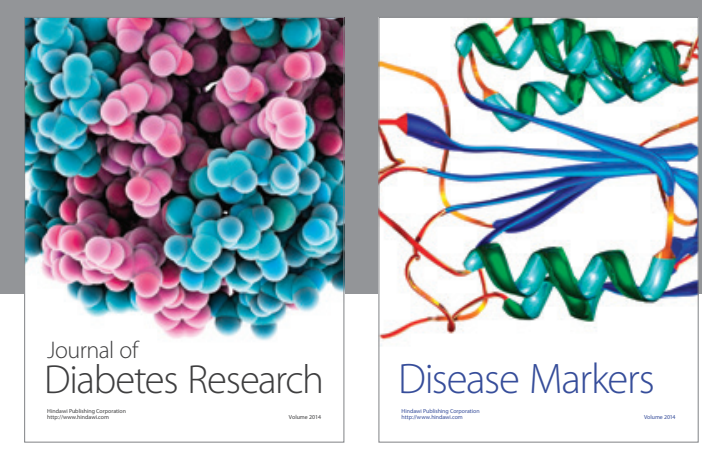

Disease Markers
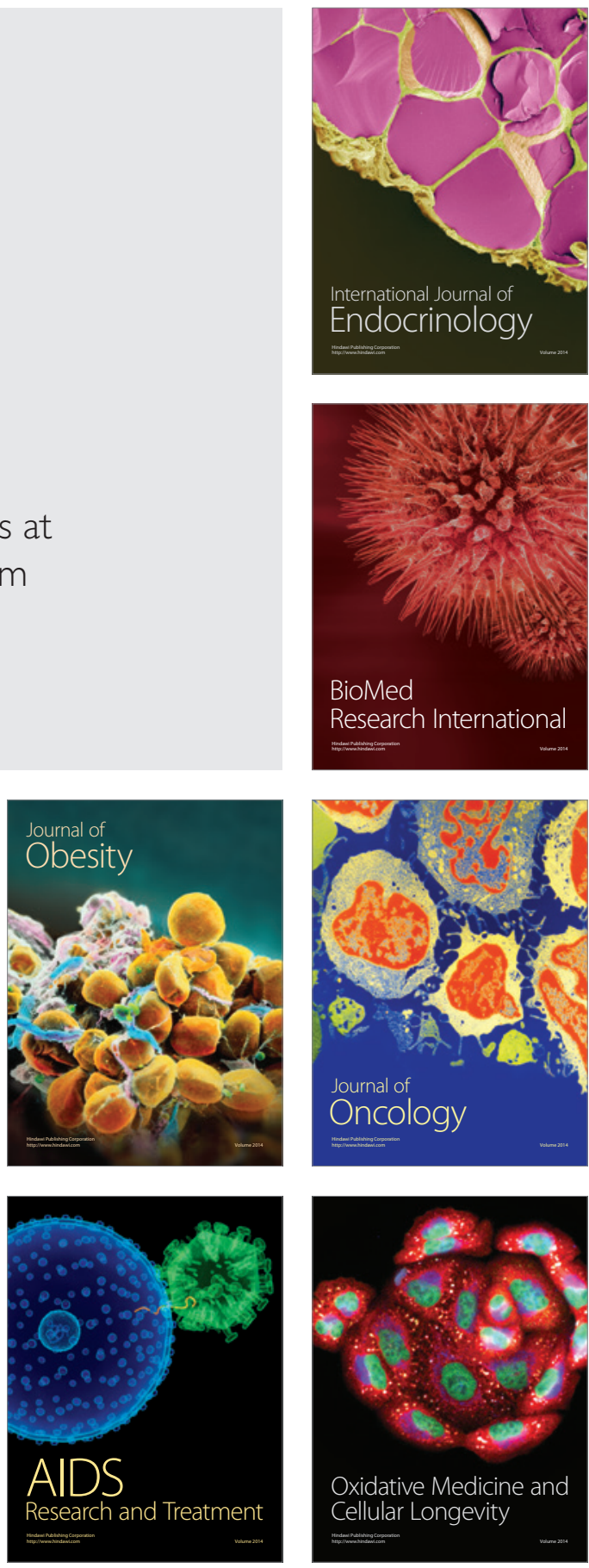